\title{
Gestão dos resíduos sólidos no Município de Queimadas (Estado da Paraíba, Nordeste do Brasil) segundo a Política Nacional de Resíduos Sólidos
}

\section{Priscila Santos Souza ${ }^{1}$, , Nayara Ariane Laureano Gonçalves ${ }^{1}$, Rosires Catão Curi ${ }^{2}$}

${ }^{1}$ Programa de Pós-Graduação em Recursos Naturais. Universidade Federal de Campina Grande. Rua Aprígio Veloso, 882. Bairro Universitário. Campina GrandePB. Brasil (CEP 58429-900). *E-mail: priscila.s_souza@hotmail.com.

${ }^{2}$ Universidade Federal de Campina Grande. Centro de Ciências e Tecnologia, Departamento de Engenharia Civil. Rua Aprígio Veloso, 882. Bairro Universitário. Campina Grande-PB. Brasil (CEP 58429-900).

Resumo. Embora a Política Nacional de Resíduos Sólidos (PNRS) por meio da Lei no $12.305 / 2010$ preconize que todos os municípios brasileiros adotem uma forma mais socioambientalmente consciente para tratar as questões referentes aos Resíduos Sólidos Urbanos (RSU), muitos municípios ainda não conseguiram se adequar às normas legais, implicando em sérios prejuízos, principalmente à qualidade de vida da população e do ambiente. Deste modo, a presente pesquisa foi desenvolvida em novembro de 2016, e teve por finalidade avaliar a forma de coleta, tratamento e disposição de resíduos sólidos no Município de Queimadas (Estado da Paraíba, Nordeste do Brasil), através da aplicação do Modelo PressãoEstado-Resposta (P-E-R) adaptado, que usou como dados de entrada o Plano de Gerenciamento Integrado de Resíduos Sólidos do município. Além disso, foi feito um checklist para analisar a atual disposição e tratamento de cada tipo de resíduo, investigando se o processo de gerenciamento está em conformidade com o que determina a PNRS. Diante disto, constata-se que o Município de Queimadas, em sua quase totalidade não cumpre o que preconiza a legislação nacional pertinente, quanto aos modos mais indicados de gerenciamento dos resíduos, com vistas a diminuir os impactos ambientais gerados. No entanto, a aplicação do modelo P-E-R permitiu observar que foram propostas melhorias por parte dos governantes de modo a buscar sanar ou mitigar as inadequações referentes aos RSU gerados pela população de Queimadas.

Palavras-chave: Gerenciamento de resíduos sólidos urbanos; Modelo P-E-R; Política Nacional de Resíduos Sólidos; Saúde ambiental.

Abstract. Management of solid waste in the Municipality of Queimadas (State of Paraíba, Northeast of Brazil) according to the National Solid Waste Policy. Although the Brazilian Solid

Recebido:

$13 / 07 / 2018$

Aceito:

08/08/2018

Publicado:

$31 / 08 / 2018$

Acesso aberto

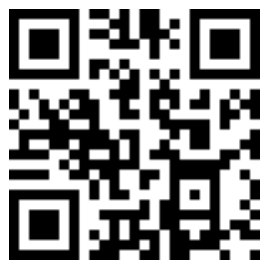

ORCID

(1) 0000-0002-2406-5066 Priscila Santos Souza

(1) 0000-0001-9154-3358 Nayara Ariane Laureano Gonçalves

(D) 0000-0001-6924-4204 Rosires Catão Curi 
Waste Policy (PNRS) through the Law $12.305 / 2010$ press that all Brazilian municipalities adopt a more socially and environmentally conscious way to deal with the issues relating to urban solid waste (RSU), many municipalities have not yet been able to adapt, resulting in serious damage, especially to the quality of life of the population and the environment. Thus, the present research was developed in November of 2016, and had the purpose of evaluating the form of solid waste collection, treatment and disposal in the Municipality of Queimadas (State of Paraíba, Northeast of Brazil), through the application of PressureState-Response adapted model, using as input data the Integrated Solid Waste Management Plan of the municipality. In addition, a checklist has been made to analyze the current disposition and treatment of each type of waste by investigating whether the management process is in accordance with the PNRS. In view of this, it can be seen that the municipality, in its almost totality, does not comply with the national legislation, regarding the most suitable modes of waste management, in order to decrease the environmental impacts. However, the application of the P-E-R model allowed to observe that improvements were proposed by the government in order to remedy or mitigate the inadequacies regarding to RSU generated by the population of Municipality of Queimadas.

Keywords: Urban solid waste management; P-E-R Model; Brazilian Policy on Solid Waste; Environmental health.

\section{Introdução}

Nos últimos anos, evidencia-se uma crise socioambiental de grande repercussão, decorrente do progresso tecnológico e do modelo de consumo adotado pela população mundial, que vem desencadeando o aumento da geração de resíduos e a exploração desenfreada dos recursos naturais. Essa situação tem implicado em algumas mudanças, provocado uma reflexão em relação aos problemas ambientais e instigado à procura por alternativas que possam amenizá-los.

Segundo Lyra (2009), o aumento da conscientização referente aos problemas ambientais permite que a sociedade e o Estado tenham uma postura mais proativa em relação à mitigação destes problemas que impactam diretamente nas estratégias competitivas das organizações.
Nesta perspectiva, a problemática da enorme quantidade de resíduos sólidos urbanos (RSU) gerados e a incorreta forma disposição dos mesmos, além da ausência de tratamento em muitas localidades, repercute em intensas discussões e representa uma preocupação constante no cenário mundial, constituindo, portanto, um dos grandes desafios para os gestores públicos. Na tentativa de regularizar essa situação e propor alternativas que viessem solucionar ou minimizar os impactos ao meio ambiente foi promulgada a Lei no $12.305 / 2010$ (Brasil, 2010), que instituiu a Política Nacional de Resíduos Sólidos (PNRS).

Diante disso, a PNRS estabelece princípios, objetivos, instrumentos e diretrizes para gestão integrada e gerenciamento dos resíduos sólidos indicando as responsabilidades dos geradores, do poder público e dos 
consumidores. Com isso, define princípios importantes: prevenção e precaução, poluidor-pagador, eco eficiência, da responsabilidade compartilhada, reconhecimento do resíduo como bem econômico e de valor social, do direito da informação e controle social, entre outros (Brasil, 2010).

A legislação ambiental brasileira abrange uma serie de normas legais que estão associadas à Lei no 12.305/2010, sendo aplicadas de maneira integrada, quando o assunto se refere à gestão, manejo e destinação final de resíduos sólidos (Cavalcante et al., 2014). Além disso, a partir da PNRS, fica determinado que os municípios devam construir aterros sanitários adequados ambientalmente, onde poderão ser depositados apenas aqueles resíduos sem qualquer possibilidade de reaproveitamento (Oliveira et al., 2015).

No entanto, atualmente ainda prevalece em muitos municípios $\mathrm{o}$ depósito inadequado de resíduos, em vazadouros a céu aberto, em áreas próximas da zona urbana e em aterros sanitários que não atendem as normativas, ou ainda, aqueles que extrapolam suas capacidades em curto prazo e acabam por se transformarem em verdadeiros lixões. Somado a isso, ainda identifica-se a falta de tratamento de resíduos passíveis de recuperação e reaproveitamento.

Em relação aos impactos ambientais, estes podem ser físicos, que incluem a erosão, alteração na capacidade de uso do solo, dano ao relevo, emissão de odores, queima de resíduos, águas subterrâneas comprometidas, geração de chorume; bióticos, como a redução da biota, redução da biodiversidade nativa, redução da capacidade de sustentação da fauna e afugentamento de animais; bem como antrópicos, como a poluição visual (alteração da paisagem), poluição de áreas circunvizinhas, presença de catadores e presença de vetores de doenças (Araújo, 2015).
Nesse cenário, insere-se o Município de Queimadas, que possui um lixão a céu aberto, denominado Lixão Sítio Zé Velho, próximo ao perímetro urbano, existindo há 27 anos, e sendo, um ambiente favorável a uma série de impactos socioambientais, como indicados no Plano de Gerenciamento Integrado de Resíduos Sólidos, elaborado pela Prefeitura Municipal de Queimadas (PMQ) (PMQ, 2016).

Nesta perspectiva, torna-se imprescindível identificar uma problemática de caráter ambiental, caracterizar e analisar o conflito socioambiental estabelecido, compreender a inserção e interação dos atores envolvidos, além de observar quais as medidas estão sendo tomadas para que a situação possa ser amenizada ou sanada.

Assim, esta pesquisa teve por objetivo principal avaliar a atual forma de coleta, tratamento e disposição de resíduos sólidos no Município de Queimadas, através da aplicação do Modelo Pressão-Estado-Resposta (P-ER). O modelo foi aplicado através da análise dos conflitos socioambientais envolvendo o gerenciamento dos RSU do município estudado, da avaliação do Plano de Gerenciamento Integrado de Resíduos Sólidos (PGIRS) de Queimadas, para saber se o mesmo está de acordo com as normas legais estabelecidas; e da descrição das principais ações e iniciativas desenvolvidas pelos gestores relacionadas à Educação ambiental e conscientização da população sobre os RSU.

\section{Fundamentação teórica}

Resíduos Sólidos Urbanos (RSU)

Comumente denominado de lixo, o resíduo sólido urbano, pode ser considerado como uma das causas agravantes para a crise ambiental e, neste sentido, a tecnologia ambiental pode ser usada como meio para reverter a situação. Tendo perdido o significado no mundo acadêmico e jurídico, o termo 
"lixo" vem sendo substituído pela denominação resíduo, devido ser passível de tratamento e/ou reaproveitamento (Voloch, 2012).

De acordo com a Lei $\mathrm{n}^{\mathrm{o}}$ $12.305 / 2010$, art. 30, inciso XVI, os resíduos sólidos (RS) são definidos como todo material, substância, objeto ou bem descartado resultantes de atividades humanas em sociedade, a cuja destinação final se procede, se propõe proceder ou está obrigado a proceder, nos estados sólido ou semissólido, bem como gases contidos em recipientes e líquidos cujas particularidades tornem inviável o seu lançamento na rede pública de esgotos ou em corpos d'água, ou exijam para isso soluções técnicas ou economicamente inviáveis em face da melhor tecnologia disponível (Brasil, 2010).

Para Lourenço (2014), é de fundamental importância que seja realizada uma classificação dos resíduos sólidos, para o planejamento e gestão eficiente. Assim, para que ocorra a destinação apropriada de um determinado tipo de resíduo, faz-se necessário conhecê-lo, pois é de acordo com suas características que será inserido em um grupo e ser classificado.

De forma geral a ABNT NBR 10004:2004 (ABNT, 2004), classifica os resíduos em: resíduos classe I (Perigosos), que tem por características a Inflamabilidade, Corrosividade, Reatividade, Toxicidade, e Patogenicidade; resíduos classe II (Não perigosos), divididos em resíduos classe II A (Não inertes), que não se enquadram nas classificações de resíduos classe I ou classe II B, e podem apresentar biodegradabilidade, combustibilidade ou solubilidade em água; Já os resíduos classe II B (Inertes), são aqueles que, quando amostrados, segundo a ABNT NBR 10007:2004 (ABNT, 2004), e submetidos à testes com água destilada ou desionizada, conforme ABNT NBR 10006:2004 (ABNT, 2004), não haja solubilização de constituintes a concentrações superiores aos padrões de potabilidade de água, excetuando-se aspecto, cor, turbidez, dureza e sabor.

Bartholomeu et al. (2011), agrupa os RS em dois grandes grupos: o primeiro deles refere-se aos RSU, que compreendem os resíduos domésticos ou residenciais, comerciais e públicos; o segundo tipo nomeia-se de Resíduos Especiais, e compreendem os resíduos industriais, da construção civil, radioativos, de portos, aeroportos e terminais rodoferroviários, agrícolas, e de serviço de saúde.

Tratando-se de RSU, eles ainda podem ser classificados de acordo com a origem de sua geração, correspondendo aos resíduos gerados nas residências, nos estabelecimentos comerciais, nos logradouros públicos e nas inúmeras atividades desenvolvidas pela sociedade, além dos resíduos de varrição de ruas e praças. Esses resíduos são compostos por materiais putrescíveis, papéis/ papelões, plásticos, madeiras, metais, vidros e outros materiais (Reis, 2012).

No Brasil, o que é determinado pela legislação, é que seja da responsabilidade do setor público todo o cuidado com os resíduos sólidos, no entanto, até o momento, há municípios que não atendem ao que é estabelecido pelas Leis, trazendo riscos sociais $\mathrm{e}$ ambientais.

\section{Legislação pertinente}

A problemática referente à gestão e gerenciamento do meio ambiente, referente aos resíduos sólidos, começa a ser tratada de forma mais intensa no cenário brasileiro, com a instituição da Política Nacional de Resíduos Sólidos no Brasil, por meio da Lei no 12.305/2010. A partir daí, tem-se uma política mais preocupada com questões referentes a não geração e reuso dos resíduos, coleta, manuseio, tratamento e disposição adequada, bem como os cuidados ambientais com as áreas de disposição e os produtos gerados são pontos que vem despertando a atenção de diversos órgãos governamentais e não governamentais (Reis, 2012). 
A Lei $\mathrm{n}^{\mathrm{o}}$ 12.305/2010, ainda define alguns Instrumentos, que além da coleta seletiva e logística reversa, que incentiva o desenvolvimento de cooperativas e associação de catadores de materiais recicláveis e o Sistema Nacional de Informações sobre a Gestão dos Resíduos Sólidos (Brasil, 2010).

Além da Política Nacional de Resíduos Sólidos (Lei no 12.305/2010), é possível identificar, dentre as políticas nacionais e legislações ambientais existentes que contemplam a questão dos resíduos sólidos, aquelas que dispõem sobre a Política Nacional de Meio Ambiente (Lei no 6.938/1981), a Política Nacional de Saúde (Lei no 3.080/1990), a Política Nacional de Recursos Hídricos (Lei no 9.433/1997), a Lei de Crimes Ambientais (Lei no 9.605/1998), a Política Nacional de Educação Ambiental (Lei no 9.795/1999), o Estatuto da Cidade (Lei no. 10.257/2001) (Silva e Mendes, 2007) e a Política Nacional de Saneamento Básico (Lei no 11.445/2007) (Pereira, 2014).

\section{Sólidos \\ Gerenciamento de Resíduos}

De acordo com a Lei $\mathrm{n}^{\mathrm{o}}$ 12.305/2010, (Brasil, 2010), o gerenciamento de resíduos sólidos pode ser definido, como o conjunto de ações a serem exercidas, direta ou indiretamente, nas etapas de coleta, transporte, transbordo, tratamento e destinação final ambientalmente adequada dos resíduos sólidos, além de disposição final ambientalmente adequada dos rejeitos, que estejam de acordo com plano municipal de gestão integrada de resíduos sólidos ou com plano de gerenciamento de resíduos sólidos.

A PNRS indica, por meio do art. $3^{\circ}$, inciso XI, que a Gestão Integrada de RSU compreende $\mathrm{o:}$

conjunto de ações voltadas para a busca de soluções para os resíduos sólidos, de forma a considerar as dimensões política, econômica, am- biental, cultural e social, com controle social e sob premissa do desenvolvimento sustentável (Brasil, 2010).

Para Baptista (2015), o que o inciso acima citado mostra é a nova forma como os resíduos sólidos são entendidos e gerenciados. A visão sobre resíduos agora assumem um contexto mais amplo e complexo, levando mais fatores em consideração, fatores esses que se estendem para olhar os resíduos como dotados de valor social, econômico e ambiental, o que antes era apenas visto como uma questão de saúde pública.

A integração na gestão dos RSU está ligada tanto à necessidade de políticas intersetoriais, quanto aos aspectos sociais, ambientais e econômicos envolvidos no vértice do saneamento ambiental. A importância dessa gestão de forma integrada dos RSU, é evidenciada quando ficam claros os impactos tanto ambientais quanto à saúde humana, que podem provir do inadequado gerenciamento dos mesmos (Maiello et al, 2018).

0 gerenciamento e tratamento dos resíduos sólidos vêm sendo feito de várias formas e etapas, segundo o tipo de resíduo, iniciando com a coleta e transporte (etapa que deve ser realizada para todos os tipos de RSU), coleta seletiva, logística reversa, reciclagem e disposição final dos resíduos sólidos.

\section{Modelo Pressão-Estado- Resposta (P-E-R) \\ Segundo a classificação da OECD} (OCDE - Organização para a Cooperação e o Desenvolvimento Econômico), os indicadores ambientais podem ser organizados por meio do modelo PressãoEstado-Resposta (P-E-R) (Figura 1), que está fundamentado no conceito da causalidade: "Atividades humanas exercem pressão sobre o meio ambiente e mudam sua qualidade e a quantidade dos recursos naturais (estado). A sociedade responde a estas mudanças através de políticas ambientais, econômicas e setoriais" (OECD, 1998). 


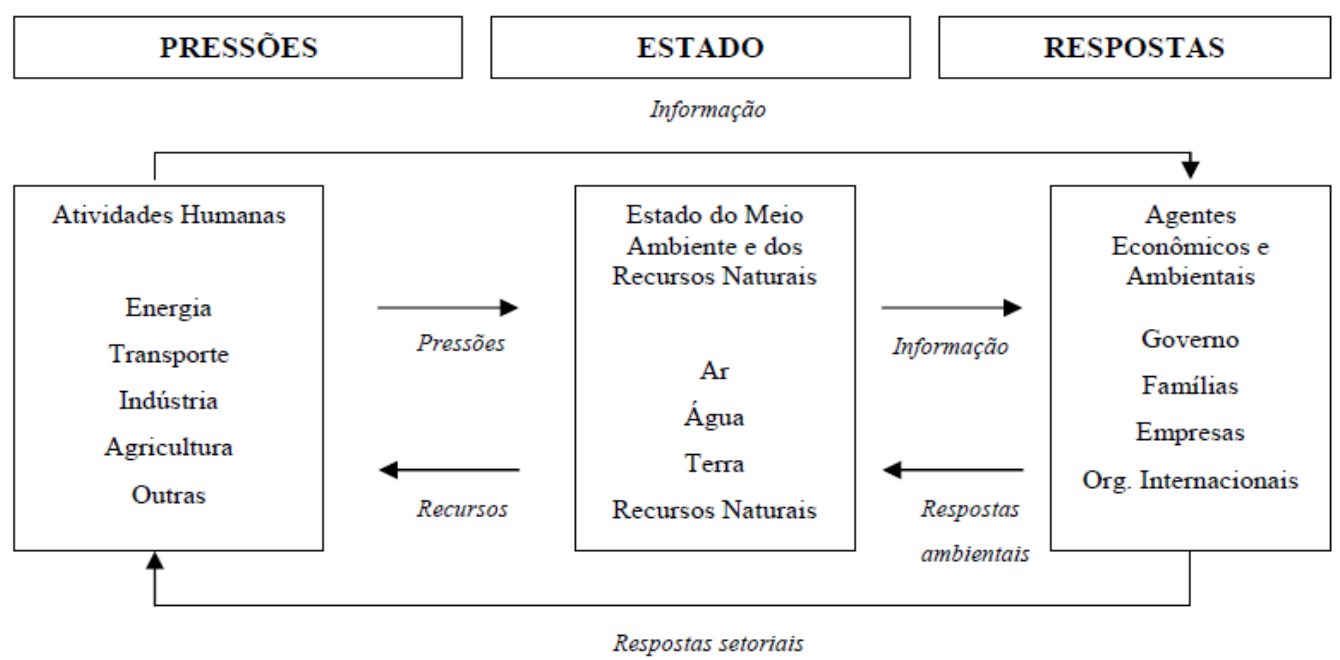

Figura 1. Modelo P-E-R. Fonte: OECD (1998).

\section{Material e métodos}

$\mathrm{Na}$ perspectiva metodológica, a presente pesquisa foi realiza em novembro de 2016, e foi baseada em duas vertentes, uma de cunho documental, baseando-se na revisão do Plano de Gerenciamento Integrado de Resíduos Sólidos do Município de Queimadas, Estado da Paraíba, da legislação pertinente, além de referenciais bibliográficos. A segunda vertente, a partir de pesquisa de campo, onde foram registradas imagens, da atual forma de disposição dos resíduos, além de questionamentos levantados junto ao órgão responsável pela gestão dos mesmos e com a representante dos catadores do Município de Queimadas.

A partir do registro fotográfico, da análise do PGIRS do município, foi organizado um check list para analisar a atual disposição e tratamento de cada tipo de resíduos, em comparação ao que preconiza a Política Nacional de Resíduos Sólidos, além de adaptar a aplicação do modelo P-E-R realizado pelos autores Beck; Araújo e Cândido (2009) fundamentada no modo cíclico, onde estes definiram três estágios classificados como Crítico, Alarmante e Preocupante e representados por figuras.
Diante disso, no presente estudo ao adaptar a aplicação do referido modelo a análise foi organizada no Estágio Crítico, sendo coletadas informações para explicar as pressões (P) evidenciadas ao longo dos anos e o estado (E) que se encontra o meio ambiente decorrente da geração e deposição inadequada de resíduos, além das respostas (R) mencionadas pelos representantes do governo.

\section{Mapeamento dos conflitos socioambientais}

Em visita ao município, foram entrevistados a líder dos catadores, que relatou os problemas enfrentados pelos mesmos, tais como a informalidade, a escassa ajuda oferecida pelo poder público, a falta de equipamentos apropriados para a catação e a migração de muitos trabalhadores advindos de Campina Grande/PB, após o fechamento do Lixão municipal.

Assim como, o Secretário de Planejamento e Infraestrutura de Queimadas, que informou a cerca da atual disposição e tratamento dos resíduos do munícipio, além do Plano de Gerenciamento, que ainda não foi posto em prática, e da entrada de Queimadas no Consórcio Intermunicipal para a 
Gestão dos Resíduos Sólidos do Cariri Oriental e Região (CIGRESCOR), que já conta com a adesão de 11 municípios, e tem como finalidade da construção de um aterro consorciado, tentando solucionar a problemática de destinação final.

Além disso, observou-se a utilização de propriedade rural para a deposição inadequada de resíduos sólidos urbanos (RSU), o Lixão Zé Velho, localizado no Sítio Zé Velho, bem como a degradação do meio ambiente e da qualidade de vida da população no seu entorno, e em especial, dos catadores de RSU, o que ocorre devido ao não cumprimento da legislação.

\section{Localização da área de estudo}

0 conflito analisado nesta pesquisa se localiza do Município de Queimadas, que está localizado na superfície do Planalto da Borborema no Estado da Paraíba. A sede do município dista cerca de $19 \mathrm{~km}$ do centro da Município de Campina Grande, segundo maior centro urbano da Paraíba, e 133,8 km de João Pessoa, o mesmo ocupando uma área de $518 \mathrm{~km}^{2}$ e população estimada em 44.214 habitantes (IBGE, 2017). O Lixão Zé Velho localiza-se a aproximadamente $1 \mathrm{~km}$ do Açude Zé Velho, 1,2 km da BR-104 e 4,2 km da sede municipal (Figura 2).

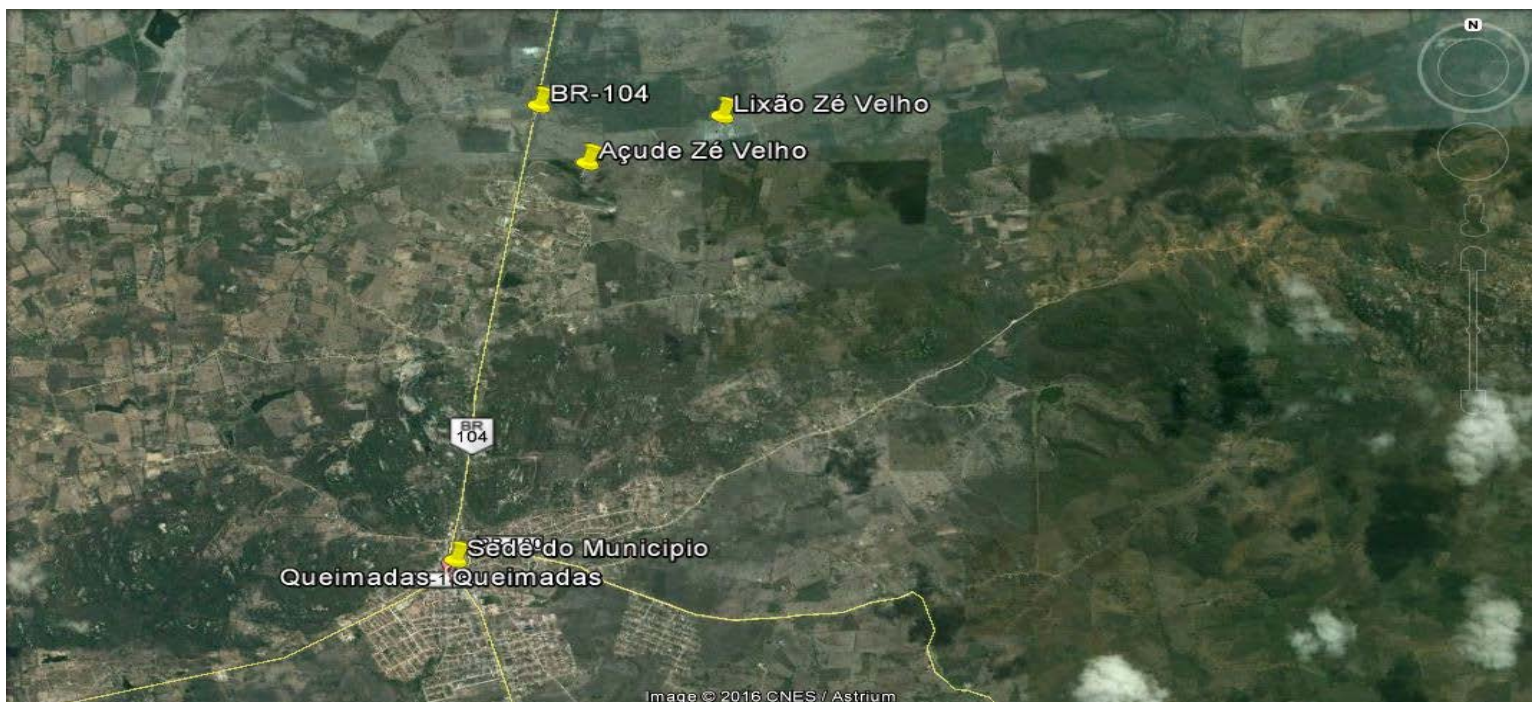

Figura 2. Localização geográfica do município de Queimadas e do Lixão Zé Velho. Fonte: Google Earth, 2016.

\section{Resultados e discussão}

\section{A Problemática dos resíduos sólidos urbanos no Município de Queimadas}

Segundo a Prefeitura Municipal de Queimadas (PMQ, 2016), através do Plano de Gerenciamento de Resíduos Sólidos do município a destinação final dos resíduos sólidos (RS) não é ambientalmente adequada, estes são dispostos em um lixão a céu aberto, denominado "Lixão Sítio Zé Velho" existindo há 27 anos, localizado em um terreno da prefeitura, em uma área de fácil acesso e de aproximadamente 6 hectares, distante cerca de $5,5 \mathrm{~km}$ do centro do município, 1,2 do Açude Zé Velho e situado a $1 \mathrm{~km}$ da BR 104, principal acesso ao Município de Campina Grande. 
Assim, constata-se que os resíduos sólidos urbanos (RSU) destinados a esse lixão não recebem nenhum tratamento, não são compactados, nem aterrados e o chorume, líquido formado a partir da decomposição dos resíduos, é liberado no solo, implicando na exalação para a atmosfera de gases de efeito estufa, destacando metano $\left(\mathrm{CH}_{4}\right)$ e dióxido de carbono $\left(\mathrm{CO}_{2}\right)$, resultantes da decomposição anaeróbica da matéria orgânica e queima (PMQ, 2016).

O Município de Queimadas possui uma população estimada em 44.214 habitantes (IBGE, 2017). Desse modo, considerando-se essa população, os estudos municipais estimam que 31.333 kg de RSU sejam destinados diariamente ao lixão do município, somando um total de 11.279.880 kg ao ano (PMQ, 2016).

Nessa perspectiva, a Prefeitura Municipal de Queimadas em conjunto com as prefeituras de municípios circunvizinhos, criaram e formalizaram um Consórcio Intermunicipal para a Gestão dos Resíduos Sólidos do Cariri Oriental e Região (CIGRESCOR), com a finalidade de encontrar uma solução para a problemática da destinação final dos RSU, propondo alternativas técnicas, priorizando, a realização de estudos para o uso de tecnologias limpas para o tratamento de resíduos.

A coleta seletiva ainda é algo inexistente no município, entretanto, algumas iniciativas como 0 realinhamento do roteiro do plano de coleta, a intensificação de campanhas de divulgação sobre a melhor maneira de separar os resíduos envolvendo a comunidade e os catadores estão sendo executadas para melhorar o processo de coleta desses resíduos.

Nesse sentido, o Programa Cidade Educadora visa abranger a implantação de uma Política Municipal de Educação Ambiental como uma estratégia de integração entre as atividades que deverão ser desenvolvidas. Assim, essa política ambiental tem como finalidade promover a participação da sociedade na política de gestão ambiental e, com isso, transformar a população em atores sociais comprometidos com as problemáticas ambientais presentes no município (PMQ, 2016).

O Município de Queimadas não oferece o Gerenciamento Integrado de resíduos Sólidos, consistindo a gestão desse setor apenas focada na coleta, transporte e destinação final, distanciando-os do local de origem. Esse caso é considerado preocupante, assim como muitos outros municípios da sua região (PMQ, 2016).

Com isso se faz imprescindível um ajustamento do município a Lei no 12.305/2010 (Brasil, 2010), que tem como uma das finalidades essenciais, priorizar a gestão de resíduos, a obrigatoriedade de não geração, redução, reutilização, reciclagem, tratamento dos resíduos sólidos e disposição final ambientalmente adequada dos rejeitos.

Referente à pesquisa observacional, foram registrados a forma de disposição, no Lixão Zé Velho, dos resíduos gerados pelo município de Queimadas-PB, constatando-se que além da grande proximidade com o mesmo, com a BR-104, com o açude Zé Velho e com algumas propriedades rurais habitadas, dessa forma, trazendo risco à população, a parcela mais atingida é aquela que por falta de melhores condições, trabalha e reside no local, os catadores de RSU.

Inicialmente, no caminho que liga a BR-104 ao Sítio Zé Velho, onde se localiza o Lixão Zé Velho, é possível observar a presença de resíduos espalhados pelo chão no percurso, o que tem a capacidade de afetar diretamente as pessoas que moram em propriedades naquela área. Esses resíduos são capazes de atrair animais, insetos e vetores de doenças (Figura 3a). A transmissão de doenças provocadas pela ação dos vetores é feita, pois estes encontram nos resíduos, condições adequadas para a sua proliferação (Siqueira e Morais, 2009). 
Após o trajeto para chegar ao Lixão, os caminhões basculantes são descarregados e os catadores prontamente vão separar os materiais que podem ser reaproveitados com a reciclagem, ou até aqueles que os mesmos consideram de interesse para o seu próprio uso, o que inclui até mesmo restos de alimentos, o que oferecem alto grau de contaminação (Figura 3b).

Como o município não possui um grupo de catadores formais, possibilitando a cooperação entre os mesmos e o apoio dos órgãos públicos, cada catador reserva em locais préselecionados pelos mesmos, aquilo que conseguiu selecionar como material reciclável, os quais são vendidos para "atravessadores", quando em quantidade suficiente para encher um caminhão (Figura 3c).

Por conta do pouco que se consegue lucrar como catador no munícipio, muitos dos que trabalham no Lixão não tem condições de ter um local digno para habitar, por isso, constroem barracas em meio aos resíduos e ali passam a residir com sua família, o que traz um risco ainda maior para essas pessoas, devido ao contato dia-a-dia com uma área que oferece uma altíssima taxa de risco de contaminações, dentre outras doenças, como mostra a (Figura 3d). 0 que reflete na deterioração da sua qualidade de vida, enquanto ambiente de trabalho, familiar e pessoal (Cavalcante, 2011).

Outra preocupação visualizada é a constante presença de animais no local, sendo visto com maior frequência, urubus e cachorros, que vão em busca de se alimentar de restos orgânicos. Estes mesmos animais são passiveis de contraírem doenças, e tendo contato com humanos, podem infectá-los. 0 mesmo pode ser aplicado a insetos que se proliferam nesses locais (Figura 3e).

A proximidade com os resíduos predispõe os animais e o homem a variadas doenças como salmonelose, toxoplasmose, leptospirose, cólera, disenteria, cisticercose e giardíase (Valente et al., 2016).

0 descaso com uma forma de tratar e reaproveitar o máximo de resíduos possíveis, além de uma disposição mais adequada, oferecendo menor risco socioambiental, como é o caso dos aterros sanitários, foi capaz de tornar uma área antes rural, em proximidade a outras propriedades, a BR-104, açude e a própria sede do município, em uma área de alto risco, principalmente à qualidade de vida e degradação ambiental (Figura 3f).

Quanto aos lixões Queiroz e Vieira (2018), relatem que:

Além do problema da falta de espaço, existe o do manejo inadequado dos resíduos sólidos que pode provocar problemas de saúde à população através da proliferação de vetores de doenças, como roedores e insetos e odores desagradáveis. Ademais, a destinação e o tratamento inapropriados do resíduo sólido podem provocar problemas ambientais, através da poluição do solo, ar e água, sendo necessário um plano de manejo dos RSU (Queiroz e Vieira, 2018:142).

Além da avaliação em campo da situação do município quanto à disposição e tratamento dos resíduos do mesmo, realizou-se um checklist para comprovar se o que constava no Plano de Gerenciamento Integrado como sendo feito em relação a cada tipo de material se adequava ao que discorre a Lei $\mathrm{n}^{\mathrm{o}}$ 12.305/2010 (Tabela 1). 


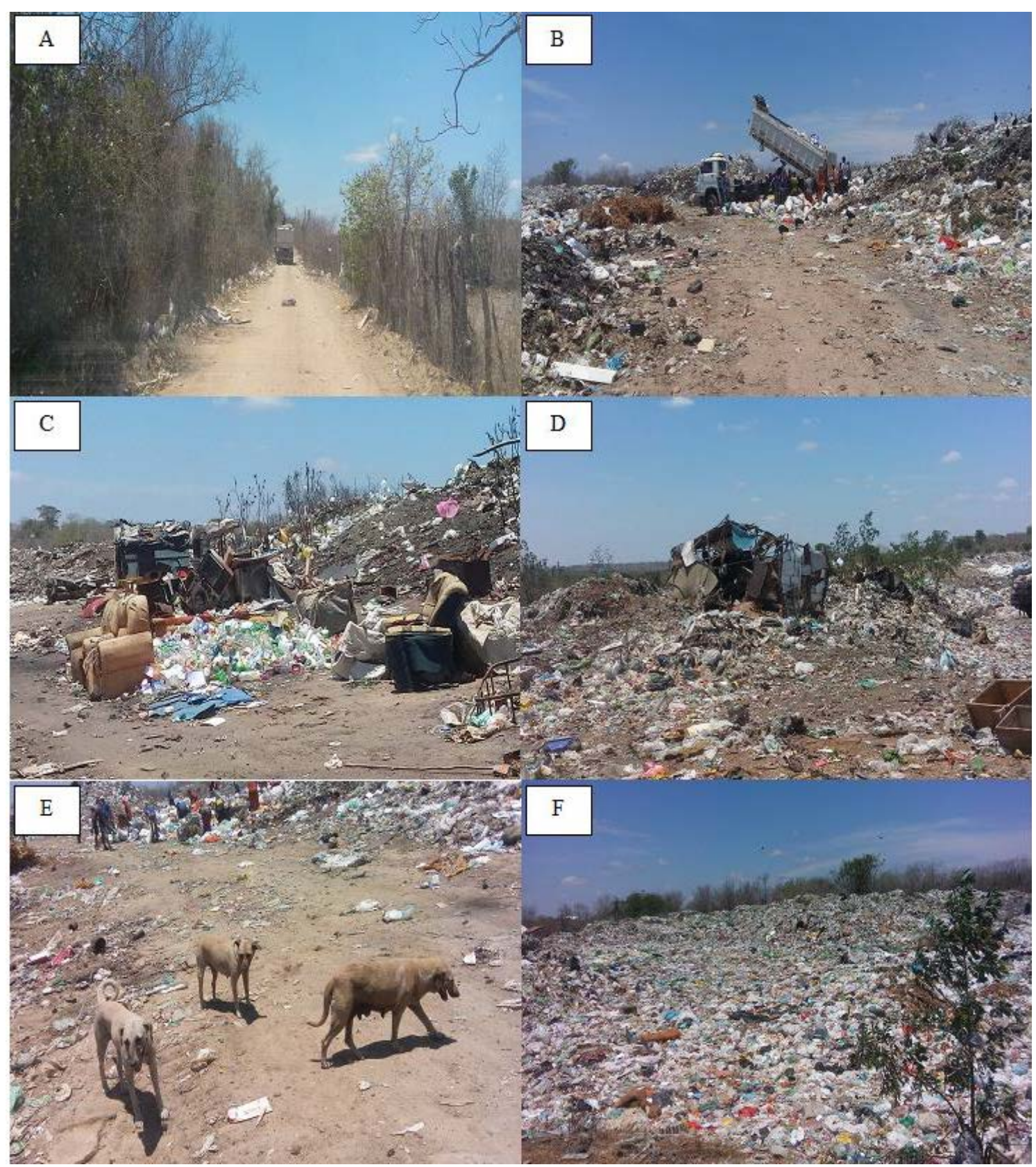

Figura 3. Caracterização Visual do Lixão Zé Velho, 2016. (a) Estrada que vai da zona urbana em direção ao Lixão; (b) Descarregamento de resíduos e a presença de catadores; (c) Materiais separados para a reciclagem; (d) Abrigo de catadores; (e) Presença de animais; (f) Mar de descaso.

Dos diferentes tipos de resíduos gerados pelo município, apenas os referentes aos Serviços de Saúde e os Agrossilvopastoris recebem destinação adequada ao que diz respeito à PNRS, já que os primeiros são recolhidos por empresa terceirizada e incinerados, e os segundos são utilizados no meio rural, com a finalidade de adubar o solo para a plantação.

Quanto aos demais tipos, apenas uma pequena parcela dos óleos comerciais são utilizados para a fabricação de sabões caseiros, além da 
coleta para reciclagem de pequena parcela dos demais resíduos, resumindo-se principalmente a plásticos, vidro, papel e alumínio. 0 restante do material é simplesmente depositado em um lixão a céu aberto, sem nenhum cuidado, controle ou tratamento.

Tabela 1. Checklist de adequação à PNRS de tratamento e disposição de resíduos sólidos, no Município de Queimadas.

\begin{tabular}{|c|c|c|}
\hline \multirow{2}{*}{ Tipos de Resíduos } & \multicolumn{2}{|c|}{ Política Nacional de Resíduos Sólidos (PNRS) } \\
\hline & Está de Acordo & Não está de Acordo \\
\hline Resíduos Sólidos Domésticos & & $\checkmark$ \\
\hline Resíduos Sólidos Comerciais & & $\checkmark$ \\
\hline Resíduos Sólidos Públicos & & $\checkmark$ \\
\hline $\begin{array}{l}\text { Resíduos Sólidos de Serviços de } \\
\text { Saúde }\end{array}$ & $\checkmark$ & \\
\hline Resíduos Sólidos de Fontes Especiais & & $\checkmark$ \\
\hline Resíduos Sólidos Agrossilvopastoris & $\checkmark$ & \\
\hline $\begin{array}{l}\text { Resíduos Sólidos de Mineração } \\
\text { Resíduo de Óleos Comerciais }\end{array}$ & n.i. & n.i. \\
\hline
\end{tabular}

Legenda: n.i. - Não informado

Segundo o Ministério do Meio Ambiente, o descarte inadequado de Resíduos Sólidos implica em uma série de problemas relacionados à saúde pública e ao meio ambiente, abrangendo a dimensão social decorrente do elevado número de famílias que, marginalizadas socialmente, sobrevivem dos "lixões" de onde retiram os materiais recicláveis que comercializam (MMA, 2013).

Aplicação do Modelo P-E-R: análise da situação de Queimadas

A problemática dos Resíduos Sólidos Urbanos no Município de Queimadas envolve uma série de fatores que intensificam a situação impactante vivenciada nos últimos anos. Assim, por meio desses fatores impactantes foram identificadas a partir dos dados secundários, as variáveis que demonstram as particularidades de cada fator crítico associados aos aspectos que exercem pressão (P) sobre a atividade observada, modificando o estado (E) do ambiente, ou seja, a situação que este fator se encontra. Com isso, foram selecionadas as respostas (R) da sociedade e do poder público que estão sendo efetuadas para enfrentar ou amenizar os efeitos destas agressões (pressões).

Assim sendo, ao adaptar a aplicação do modelo P-E-R, esta foi organizada no primeiro estágio de análise, definido como Crítico, sendo consideradas as modificações e evoluções observadas em um determinado período de tempo, relacionadas à atual situação dos resíduos sólidos urbanos deste município. Além disso, evidencia as ações propostas por alguns atores que tem por objetivo eliminar os problemas decorrentes da destinação final desses resíduos.

Nesse sentido, ao analisar os dados secundários por meio do que é apresentado no Plano de Gestão Integrada de Resíduos Sólidos (PGIRS) e pesquisas documentais referentes ao tema, a situação ambiental foi definida de acordo com o processo de geração, coleta e destinação dos resíduos sólidos do município de Queimadas nos últimos anos até o período atual, utilizando como 
base o modelo descrito anteriormente, acompanhando as evoluções e propondo melhorias. A Figura 4 apresenta o Modelo
P-E-R- Estágio Crítico, adaptado dos autores Beck et al. (2009), para a realidade do Município de Queimadas.

PROBLEMÁTICA DOS RESÍDUOS SÓLIDOS URBANOS NO MUNICÍPIO DE

QUEIMADAS - APLICAÇÃO DO MODELO P-E-R

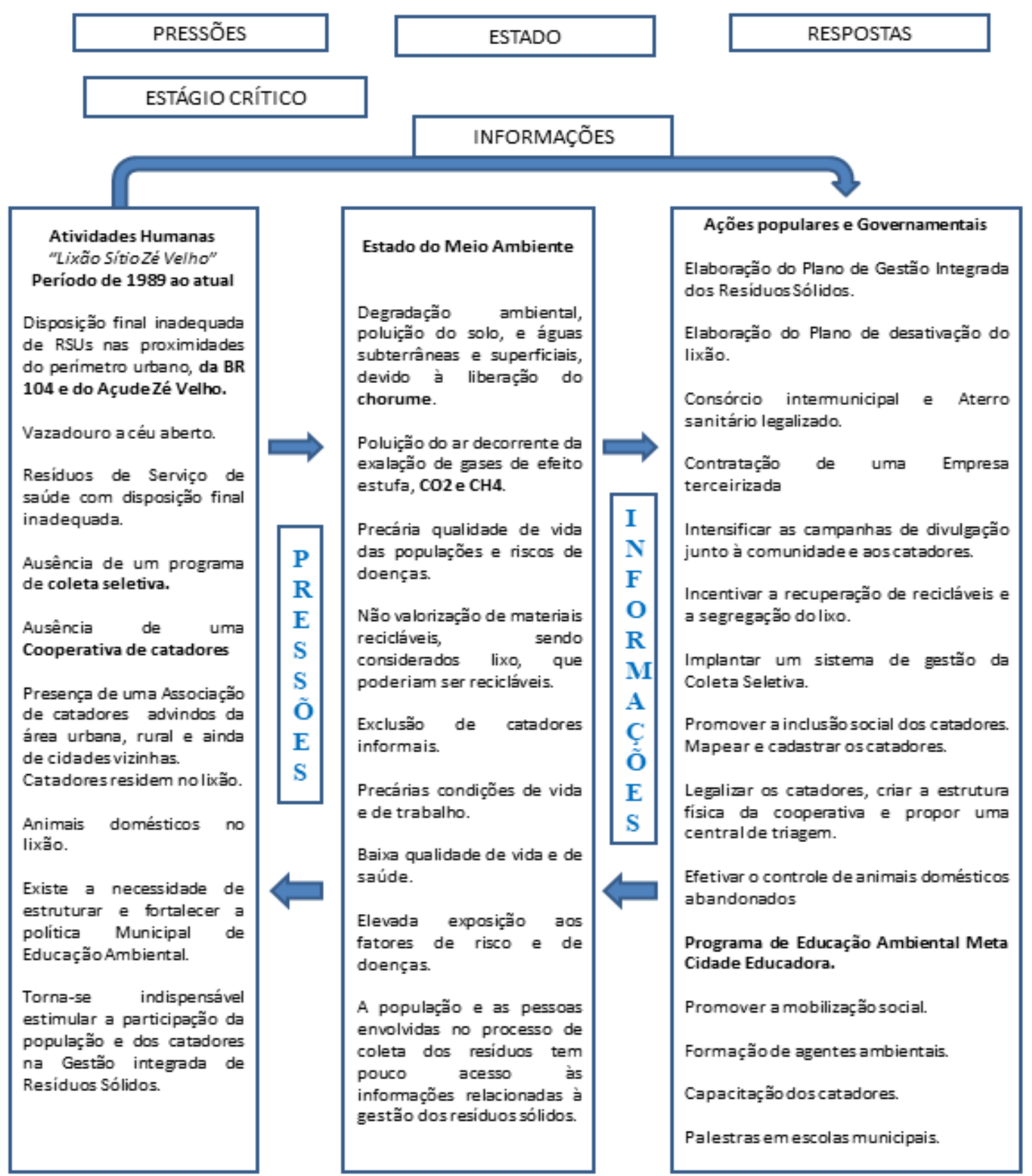

Figura 4. Aplicação do Modelo P-E-R- Estágio Crítico. Adaptado de Beck et al. (2009). 


\section{Conclusão}

Com a avaliação do Plano de Gerenciamento Integrado, constata-se que o Município de Queimadas, em sua quase totalidade não cumpre $o$ que determina a PNRS, quanto à coleta, tratamento e disposição de resíduos, com exceção dos resíduos dos serviços de saúde e os agrossilvopastoris, que possuem respectivamente, a incineração e a compostagem como formas de amenizar seus impactos sobre o meio ambiente.

Além disso, apesar de o município está em busca de sua adequação, por meio da inserção no CIGRESCOR, com a finalidade de construir um aterro sanitário consorciado, ainda há muito sendo feito para melhorar a qualidade de vida, principalmente dos que vivem no entorno do lixão, e dos catadores, além da preservação ambiental.

0 município necessita investir não somente na construção do aterro, mas na educação ambiental, no reaproveitamento de resíduos, na recuperação das áreas do atual lixão, além de organização e cuidado com os catadores, que atualmente vivem em condições sub-humanas, fazendo de suas profissões um meio formalizado de sobrevivência mais digna.

Por fim, segundo o modelo P-E-R, diante das pressões oferecidas por meio das questões humanas e do estado em que se encontra a qualidade do meio ambiente e da população afetada, os gestores passaram a estudar meios para responder às necessidades, mas para que esses planos sejam postos em prática, necessitam ainda de muito empenho e fiscalização, por meio do poder público, e mesmo por meio de ações mais participativas da própria população.

\section{Conflito de interesses}

As autoras declaram não haver conflito de interesses.

\section{Referências}

ABNT - Associação Brasileira de Normas Técnicas. ABNT NBR 10004:2004 Resíduos sólidos - Classificação. Rio de Janeiro: ABNT, 2004.

ABNT - Associação Brasileira de Normas Técnicas. ABNT NBR 10006:2004 Procedimento para obtenção de extrato solubilizado de resíduos sólidos. Rio de Janeiro: ABNT, 2004.

ABNT - Associação Brasileira de Normas Técnicas. ABNT NBR 10007:2004 Amostragem de resíduos sólidos Classificação. Rio de Janeiro: ABNT, 2004.

Araújo, T.B. Avaliação de impactos ambientais em um lixão inativo no Município de Itaporanga-PB. Campina Grande: Universidade Estadual da Paraíba, 2015. (Monografia).

Bartholomeu, D. B.; Caixeta-Filho, J. V. (Orgs.). Logística ambiental de resíduos sólidos. São Paulo: Atlas, 2011.

Baptista, V. F. As políticas públicas de coleta seletiva no Município do Rio de Janeiro: onde e como estão as cooperativas de catadores de materiais recicláveis? Revista Administração Pública, v. 49, n. 1, p. 141-164, 2015. https://doi.org/10.1590/0034-76121603

Beck, C. G.; Araújo, A. C.; Cândido, G. A. Problemática dos resíduos sólidos urbanos do Município de João Pessoa: aplicação do Modelo P-E-R. Qualitas Revista Eletrônica, v. 8, n. 3, p. 1-15, 2009. https://doi.org/ 10.18391/qualitas.v8i3.661

Brasil. Lei no 12.305, de 2 de agosto de 2010. Institui a Política Nacional de Resíduos Sólidos. Disponível em: <http://www. planalto.gov.br/ccivil_03/_ato2007-2010/ 2010/lei/112305.htm>. Acesso em: 20 jun. 2018

Cavalcante, L. P. S. Influência da organização de catadores de materiais recicláveis em associação para a melhoria da saúde e minimização de impactos socioambientais. Campina Grande: Universidade Estadual da Paraíba, 2011. (Trabalho de Conclusão de Curso).

Cavalcante, L. P. S.; Alencar, L. D.; Barbosa, E. M. Conflitos socioambientais e catadores de materiais recicláveis informais: estudo de caso em Campina Grande/PB. Revista Polêmica, v. 13, n. 1, p. 1034-1056, 2014. 
https://doi.org/10.12957/polemica.2014.96 34

IBGE - Instituto Brasileiro de Geografia e Estatística. 2017. Disponível em: $<$ https://cidades.ibge.gov.br/brasil/pb/quei madas/panorama>. Acesso em: 25 jun. 2018.

Lourenço, D. A. Análise logística da localização do aterro sanitário do CODEMP - Consórcio de Desenvolvimento Sustentável do Médio Piranhas-PB. Pombal: Universidade Federal de Campina Grande, 2014. (Trabalho de conclusão de curso).

Lyra, M. G.; Gomes, R. C.; Jacovine, L. A. G. 0 papel dos stakeholders na sustentabilidade da empresa: contribuições para a construção de um modelo de análise. Revista de Administração Contemporânea, v. 13, p.39-52, 2009. https://doi.org/10.1590/ S1415-65552009000500004

Maiello, A.; Britto, A. L. N. P.; Valle, T. F. Implementação da Política Nacional de Resíduos Sólidos. Revista de Administração Pública, v. 52, $\quad$ n. 1, p. 24-51, 2018. https://doi.org/10.1590/0034-7612155117

MMA - Ministério do Meio Ambiente. Contexto e principais aspectos. 2013. Disponível em: <http://www.mma.gov.br/ cidades-sustentaveis/residuossolidos/ politica-nacional-de-residuos-solidos/ contextos-e-principais-aspectos $>$. Acesso em: 22 jun. 2018.

OECD - Organization for Economic Co-Operation and Development. Towards sustainable development: Environmental indicators. Paris: OECD, 1998. Disponível em: <http://www.oecd.org/>. Acesso em: 16 nov. 2016.

Oliveira, A. L.; Souza, P. A.; Gonçalves, D. S.; Santos, A. F.; Bendito, B. P. C. Análise qualitativa dos impactos ambientais no meio abiótico em um depósito de resíduos sólidos. Enciclopédia da Biosfera, v. 11, n. 22, p. 184-199, 2015. https://doi.org/10.18677/ Enciclopedia_Biosfera_2015_080

Pereira, S. S. Aplicação de método multicritério e multidecisor na gestão dos resíduos sólidos urbanos da Região Metropolitana de Campina Grande/PB. Campina Grande: Universidade Federal de Campina Grande, 2014. (Tese de Doutorado). PMQ - Prefeitura Municipal de Queimadas. Plano de Gerenciamento Integrado de Resíduos Sólidos (PGIRS). Queimadas: PMQ, 2016.

Queiroz, N. T.; Vieira, E. T. V. Gestão de resíduos sólidos na zona urbana do Município de Varzelândia, Minas Gerais, Brasil: um olhar pela via da gestão municipal e impressões da população. Revista Brasileira de Gestão Ambiental e Sustentabilidade, v. 5, n. 9, p.141-156, 2018. https://doi.org/10.21438/rbgas. 050909

Reis, A. S. Tratamento de resíduos sólidos orgânicos em biodigestor anaeróbio. Recife: Universidade Federal de Pernambuco, 2012. (Dissertação de Mestrado).

Silva, E. R.; Mendes, L. A. A. M. (Ed.). Meio ambiente: experiências em pesquisa multidisciplinar e formação de pesquisadores. Rio de Janeiro: Mauad, 2007. p. 191-208.

Siqueira, M. M.; Morais, M. S. Saúde coletiva, resíduos sólidos urbanos e os catadores de lixo. Ciência \& Saúde Coletiva, v. 14, n. 6, p. 2115-2122, 2009. https://doi.org/10.1590/ S1413-81232009000600018

Valente, B. S.; Xavier, E. G.; Rodrigues, J. M.; Kivel, T. H. Impactos ambientais dos resíduos sólidos no Município de Pelotas/RS; Um olhar fotográfico. Revista Eletrônica em Gestão, Educação e Tecnologia Ambiental, v. 20, n. 1, p. 97-104, 2016. Disponível em: $<$ https://periodicos.ufsm.br/reget/article/vi ew/20000/pdf> Acesso em: 22 jun. 2018.

Voloch, L. Carbonização de resíduo sólido urbano como alternativa de tratamento e geração de energia: viabilidade de aplicação no município de Londrina/PR. Londrina: Universidade Estadual de Londrina, 2012. (Monografia). 